\title{
Phylogenomic analyses of clostridia and identification of novel protein signatures that are specific to the genus Clostridium sensu stricto (cluster I)
}

\author{
Radhey S. Gupta and Beile Gao
}

Correspondence

Radhey S. Gupta

gupta@mcmaster.ca

\author{
Department of Biochemistry and Biomedical Science, McMaster University, Hamilton, Ontario L8N \\ 3Z5, Canada
}

\section{INTRODUCTION}

The species belonging to the genus Clostridium comprise a heterogeneous assemblage that does not form a monophyletic grouping in phylogenetic trees based on different gene/protein sequences (Cato et al., 1986; Lawson et al., 1993; Stackebrandt et al., 1999; Finegold et al., 2002;

Abbreviations: ML, maximum-likelihood; MP, maximum-parsimony; $\mathrm{NJ}$, neighbour-joining.

Details of proteins and strains used in the analyses and proteins found uniquely in either C. perfringens or C. tetani E88 and an NJ tree of the set II sequences are available as supplementary material with the online version of this paper.
Wiegel et al., 2006). Many species were originally assigned to this genus based on their being Gram-positive, anaerobic rods that are capable of endospore formation (Cato et al., 1986; Cato \& Stackebrandt, 1989; Lawson et al., 1993; Finegold et al., 2002; Rood, 2006). However, these criteria led to the placement of numerous species in this genus, many of which were very distantly related to the type species of the genus, Clostridium butyricum (Johnson \& Francis, 1975; Cato et al., 1986; Lawson et al., 1993; Stackebrandt et al., 1999; Wiegel et al., 2006). Earlier work by a number of scientists, particularly by Collins, Stackebrandt and their co-workers, based on 16S rRNA gene sequences, suggested a number of important changes 
to the taxonomy of the clostridia (Lawson et al., 1993; Collins et al., 1994; Stackebrandt et al., 1999; Wiegel et al., 2006). These studies led to the transfer of many previously known Clostridium species to new genera within the family Clostridiaceae and also to new families within the Firmicutes (Lawson et al., 1993; Collins et al., 1994; Stackebrandt et al., 1999; Finegold et al., 2002; Wiegel et al., 2006). Based on the branching pattern of the clostridium species in the 16S rRNA gene tree, Collins and co-workers proposed that only a subset of the presently known Clostridium species, which form a distinct clade in the tree (cluster I), should be considered as true representatives of the genus Clostridium (i.e. Clostridium sensu stricto), and that other Clostridium species that lay outside this cluster should not be included in the genus Clostridium (Lawson et al., 1993; Collins et al., 1994). Of the current $>150$ Clostridium species with validly published names (see http://www.bacterio.cict.fr), fewer than half are part of cluster I (Wiegel et al., 2006).

Although the proposal by Collins et al. (1994) to restrict the definition of the genus Clostridium to cluster I is an important step in terms of clarifying its taxonomy, cluster I also contains some members of other genera (e.g. Anaerobacter, Eubacterium and Sarcina) (Finegold et al., 2002; Wiegel et al., 2006; Rood, 2006). Moreover, this cluster is presently defined only in phylogenetic terms, and no biochemical, molecular or phenotypic characteristic is known that is unique to members of this cluster. Therefore, in order to circumscribe and define the genus Clostridium in clearer and more definitive terms, it is important to identify molecular markers that are uniquely shared by the members of this clade. In recent years, genome sequences have become available (http://www.ncbi.nlm. nih.gov/genomes/lproks.cgi) for a large number of prokaryotic organisms, including $>130$ firmicutes, of which 15 are from Clostridium species (Nolling et al., 2001; Shimizu et al., 2002; Brüggemann et al., 2003; Myers et al., 2006; Sebaihia et al., 2006, 2007; Bettegowda et al., 2006; Seedorf et al., 2008). Comparative analyses of these and other clostridial genomes provide an unprecedented resource for discovering novel molecular characteristics that are either limited to a given species or are uniquely shared by different members of well-defined phylogenetic clades. Our recent work in this area has identified a large number of conserved indels (i.e. inserts or deletions) and whole proteins that are restricted to many higher taxonomic groups within the Bacteria (e.g. Alphaproteobacteria, Epsilonproteobacteria, Chlamydia, Actinobacteria, Cyanobacteria, Deinococcus-Thermus, Bacteroidetes, etc.; Griffiths et al., 2006; Gao et al., 2006; Gupta, 2006; Gupta \& Griffiths, 2006; Gupta \& Lorenzini, 2007; Gupta \& Mok, 2007). These newly discovered molecular markers provide valuable tools for biochemical, diagnostic, taxonomic and evolutionary studies on these bacteria (Koonin \& Galperin, 1997; Binnewies et al., 2006).

In the present work, we report phylogenetic analyses on various clostridial species whose genomes have been sequenced based on concatenated sequences for 37 conserved proteins (including 20 ribosomal proteins) that are found ubiquitously in bacteria. In accordance with earlier work, in these trees, the cluster I species were clearly distinguished from all other Clostridium species. We have also carried out comparative genomic and phylogenomic analyses to identify molecular markers that are uniquely shared by the members of the genus Clostridium or related species. These studies have identified a number of conserved indels in important proteins and also many whole proteins that are distinctive characteristics of the sequenced cluster I Clostridium species. One conserved indel that is specific for another well-resolved clostridial cluster (consisting of Clostridium thermocellum, Thermoanaerobacter species and Caldicellulosiruptor saccharolyticus) is also described. These molecular markers provide useful means of clarifying the taxonomy of clostridia and for circumscribing the genus Clostridium sensu stricto in more definitive terms.

\section{METHODS}

Phylogenetic analyses. Phylogenetic analyses were carried out based on concatenated sequence alignments for two datasets of proteins. The first of these datasets contained 37 proteins, which included 20 ribosomal proteins and 17 other highly conserved proteins, which are present in virtually all bacteria (see Supplementary Table S1, available in IJSEM Online, for a list of these proteins) (Harris et al., 2003; Ciccarelli et al., 2006). For this set of proteins (set I), sequences for 28 firmicute species, which included all of the sequenced clostridia except Clostridium novyi (where a few proteins were missing) were retrieved (for details see Supplementary Table S2). The second set (set II), which was a subset of set I, consisted of 11 proteins [alanyl-tRNA synthetase, arginyl-tRNA synthetase, elongation factor-G (EF-G), EF-Tu, EF-P, DNA gyrase A, Hsp70, RNA polymerase $\beta$ subunit, SecY, FtsY and CdsA] that are found in all of the bacteria. For this set, sequences for 26 firmicute species, which included all of the sequenced clostridia, including $C$. novyi, were retrieved (Supplementary Table S2). For Clostridium perfringens and Clostridium botulinum, where sequence information for more than one strain is available, only one strain (C. perfringens SM101 and C. botulinum ATCC 19397) was chosen. Multiple sequence alignments for these proteins were created using the CLUSTAL_X 1.83 program (Jeanmougin et al., 1998). The sequence alignments for each set of proteins were concatenated separately and then imported into Gblocks $0.91 \mathrm{~b}$ to remove poorly aligned regions (Castresana, 2000). The resulting final sequence alignments for the set I and set II proteins, which respectively consisted of 9421 and 4715 amino acids, were employed for phylogenetic analyses; protein sequence accession numbers are given on the alignments. Neighbour-joining (NJ) trees based on 1000 bootstrap replicates of these alignments were constructed using the TREECON $1.3 \mathrm{~b}$ program (Van de Peer \& De Wachter, 1994). The maximum-likelihood (ML) analysis was carried out using the $\mathrm{WAG}+\mathrm{F}$ model with gamma distribution of evolutionary rates with four categories using the TREEPUZZLE program with 10000 puzzling steps (Schmidt et al., 2002). Maximum-parsimony (MP) trees based on 1000 bootstrap replicates were computed using the MEGA 4.1 program (Tamura et al., 2007).

Identification of conserved indels specific to the clostridia. Multiple sequence alignments for these and many other proteins that have been created in our earlier work (Griffiths \& Gupta, 2004; Gao \& Gupta, 2005) were visually inspected to identify any conserved indel that was restricted to either all or specific groups of the clostridia. 
Indels that were not flanked by conserved regions were not considered. The specificities of these indels for the clostridia were evaluated by detailed BLAST searches on short sequence segments containing the indel and its flanking conserved regions. Sequence information for all indels was compiled into signature files that are presented here. For C. perfringens and C. botulinum, sequence information is available for a number of strains. The indicated indels were present in all of the sequenced strains (C. perfringens: SM101, ATCC $13124^{\mathrm{T}}$ and strain 13; C. botulinum: A strain ATCC 19397, A ATCC 3502, A strain Hall, A3 strain Loch Maree, B1 strain Okra and F strain Langeland), which have virtually identical sequences for these regions. In the alignment files, sequence information is presented for only one of the strains of each of these species (C. perfringens SM101 and C. botulinum A strain ATCC 3502).

Identification of lineage-specific proteins. To identify proteins that are specific to the cluster I species, BLASTP searches were carried out on each protein (or open reading frame) in the genomes of Clostridium tetani E88 (Brüggemann et al., 2003) and C. perfringens SM101 (Myers et al., 2006). These searches were carried out using the default parameters, without the low-complexity filter, to identify proteins where all significant hits were from this group of species (Altschul et al., 1997). The proteins that were of interest generally involved a large increase in the expected values (E-values) from the last hit for the cluster I clostridia to the first hit from any other organism. Further, the E-values of these latter hits were generally greater than $10^{-3}$, which indicates a weak level of similarity that can occur by chance (Gao et al., 2006; Gupta, 2006; Gupta \& Mok, 2007). All promising proteins were further analysed using the PSI-BLAST program (Schaffer et al., 2001) to confirm their group specificity. For all of the identified proteins, their protein identification numbers in the C. tetani $\mathrm{E} 88$ or $C$. perfringens SM101 genome, accession numbers and information regarding possible functions are provided.

\section{RESULTS}

The evolutionary relationships among the clostridia have been studied in detail primarily based on 16S rRNA gene sequences (Lawson et al., 1993; Collins et al., 1994). The availability of large numbers of genome sequences, which include more than 20 from different clostridia representing several orders and families from this class of bacteria, now provides an opportunity to study their evolutionary relationships based on sequences for multiple conserved proteins. Phylogenetic analyses based on a large dataset of concatenated sequences for multiple proteins are more reliable than those based on any single gene or protein (Rokas et al., 2003; Brown \& Volker, 2004; Belda et al., 2005; Ciccarelli et al., 2006). We have carried out phylogenetic analyses for the clostridia based on two large datasets of protein sequences. The larger of these datasets (set I) consist of 37 proteins, which form the core of all prokaryotes (Harris et al., 2003; Ciccarelli et al., 2006). The second dataset of 11 proteins is a subset of the larger dataset. Phylogenetic analyses based on concatenated sequence alignments for these proteins were carried out using the NJ, MP and ML methods.

An NJ distance tree for the clostridia based on a concatenated sequence alignment for the 37 proteins (set I) is shown in Fig. 1. The bootstrap scores of various nodes in this tree using the NJ, MP and ML methods (>50\%) are shown. The results for set II, which also included C. novyi, were very similar (Supplementary Fig. S1). As seen, the

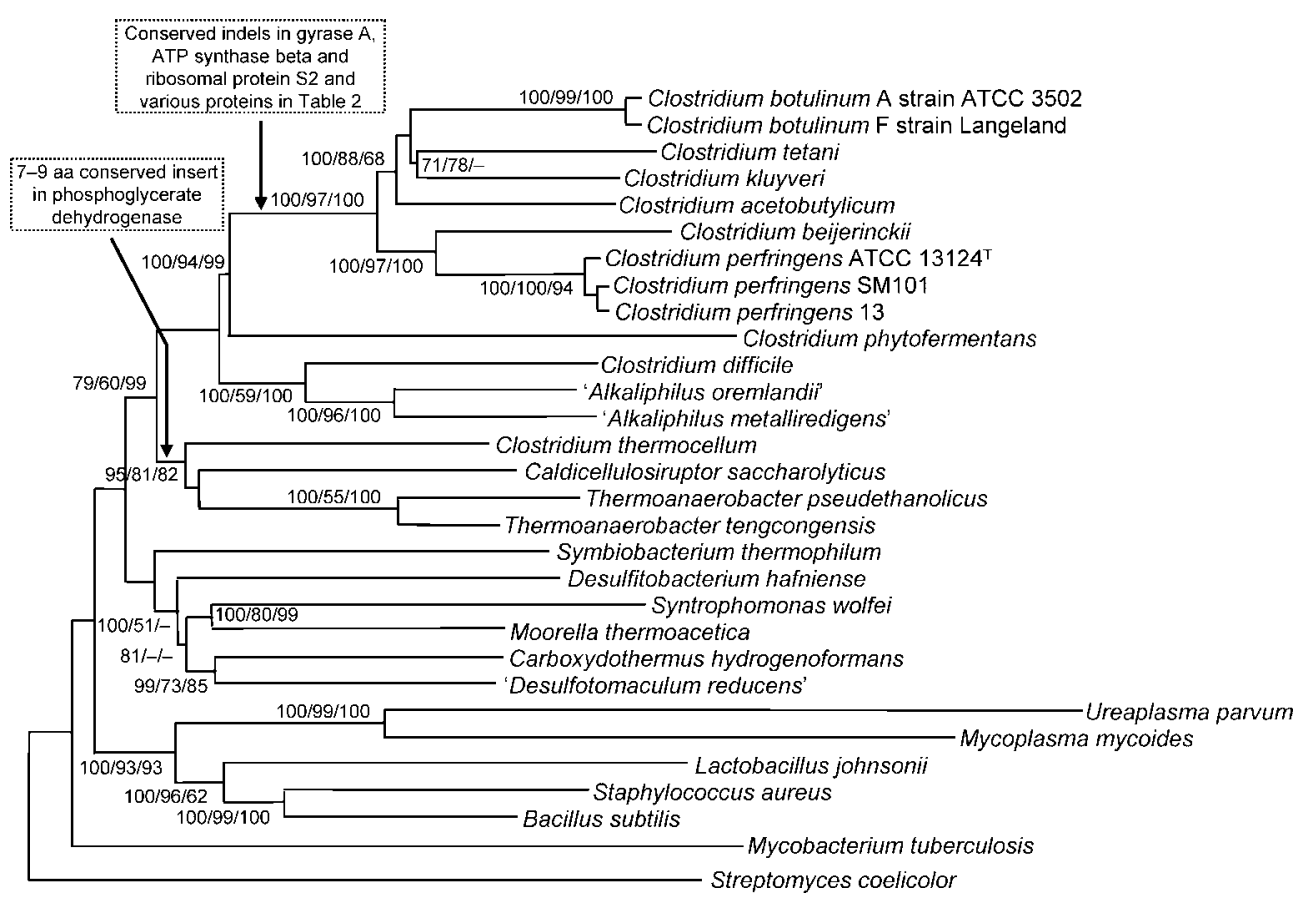

Fig. 1. NJ distance tree for the clostridia and some other firmicutes based on concatenated sequences for 37 conserved proteins. Bootstrap scores for various nodes in the NJ/MP/ML trees $>50 \%$ are indicated at nodes. The species of Clostridium cluster I as well as another cluster of clostridia that could be identified based on conserved indels are marked. 
various Clostridium species did not form a monophyletic clade in these trees. A number of Clostridium species, including C. tetani, C. botulinum, C. kluyveri, C. acetobutylicum, C. novyi, C. perfringens and C. beijerinckii, formed a well-defined clade that was recovered in $100 \%$ of the bootstrap samples (or puzzling quartets in the ML tree) and it was separated from all other clostridia by a long branch. All of the species in this clade corresponds to Clostridium sensu stricto or cluster I, as previously identified by Lawson et al. (1993) and Wiegel et al. (2006). In the NJ tree shown here,
Clostridium phytofermentans formed an outgroup of the cluster I species. However, the low bootstrap score of this combined clade and the long branch that separated this species from all other cluster I species indicated that this affiliation was not reliable. In contrast to the $\mathrm{NJ}$ tree, in both the ML and MP trees, C. phytofermentans formed an outgroup of a clade comprising Clostridium difficile and the two Alkaliphilus species. Although the grouping of C. difficile with 'Alkaliphilus metalliredigenes' and 'Alkaliphilus oremlandii was strongly supported by different methods, the

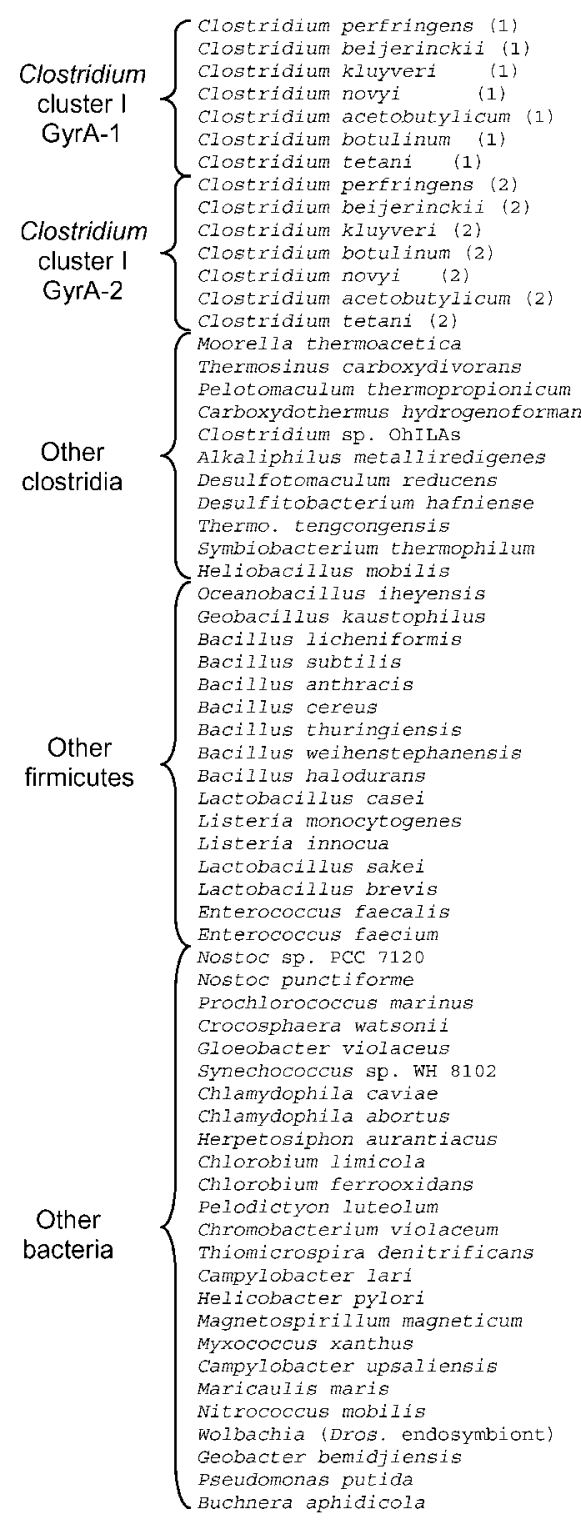
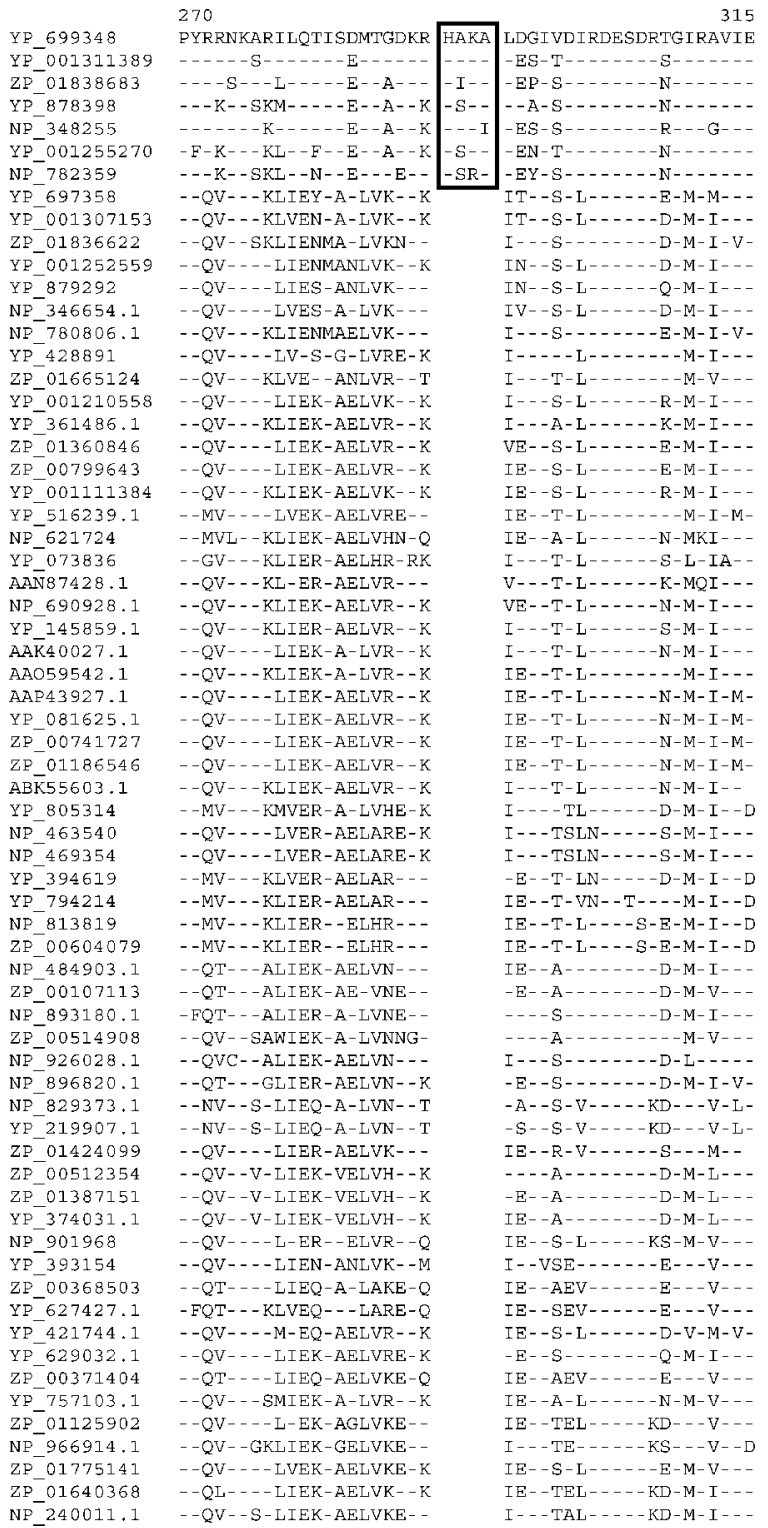

Fig. 2. Partial sequence alignment of gyrase $A$ homologues showing a 4 aa insert (boxed) in a conserved region that is found uniquely in all of the species of Clostridium cluster I for which a sequence was available. In contrast to other bacteria, the cluster I species have two different gyrase A homologues, and the identified insert is found in only one of them. Dashes (-) in this and all other sequence alignments denote identity with the amino acid on the top line. The position of the sequence in the $E$. coli protein is marked on the top. Sequence information for only representative species is presented. The indicated insert is not found in any other species. 
affiliation of $C$. phytofermentans with this clade was not reliable $(<50 \%$ bootstrap scores). Another clostridium species, $C$. thermocellum, grouped reliably with the two Thermoanaerobacter species (Thermoanaerobacter pseudethanolicus and Thermoanaerobacter tengcogensis) and Caldicellulosiruptor saccharolyticus. The above relationships, which were supported by trees based on both set I and set II sequences, confirm the inference from earlier studies that the Clostridium species are phylogenetically diverse and do not form a monophyletic group (Lawson et al., 1993; Collins et al., 1994; Stackebrandt et al., 1999; Finegold et al., 2002; Wiegel et al., 2006). The distinct branching of the cluster I species and the long branch that separated them from all other clostridia also support the proposal to recognize this group of species, which includes the majority of the medically important species, as the genus Clostridium sensu stricto (Lawson et al., 1993; Collins et al., 1994; Wiegel et al., 2006).

\section{Conserved indels in protein sequences that are specific for cluster I and other subgroups of the clostridia}

Rare genomic changes such as conserved inserts and deletions in genes/proteins that are restricted to species from phylogenetically well-defined groups provide powerful means of confirming evolutionary relationships among species as well as valuable molecular markers for taxonomic, genetic and biochemical studies (Rivera \& Lake,

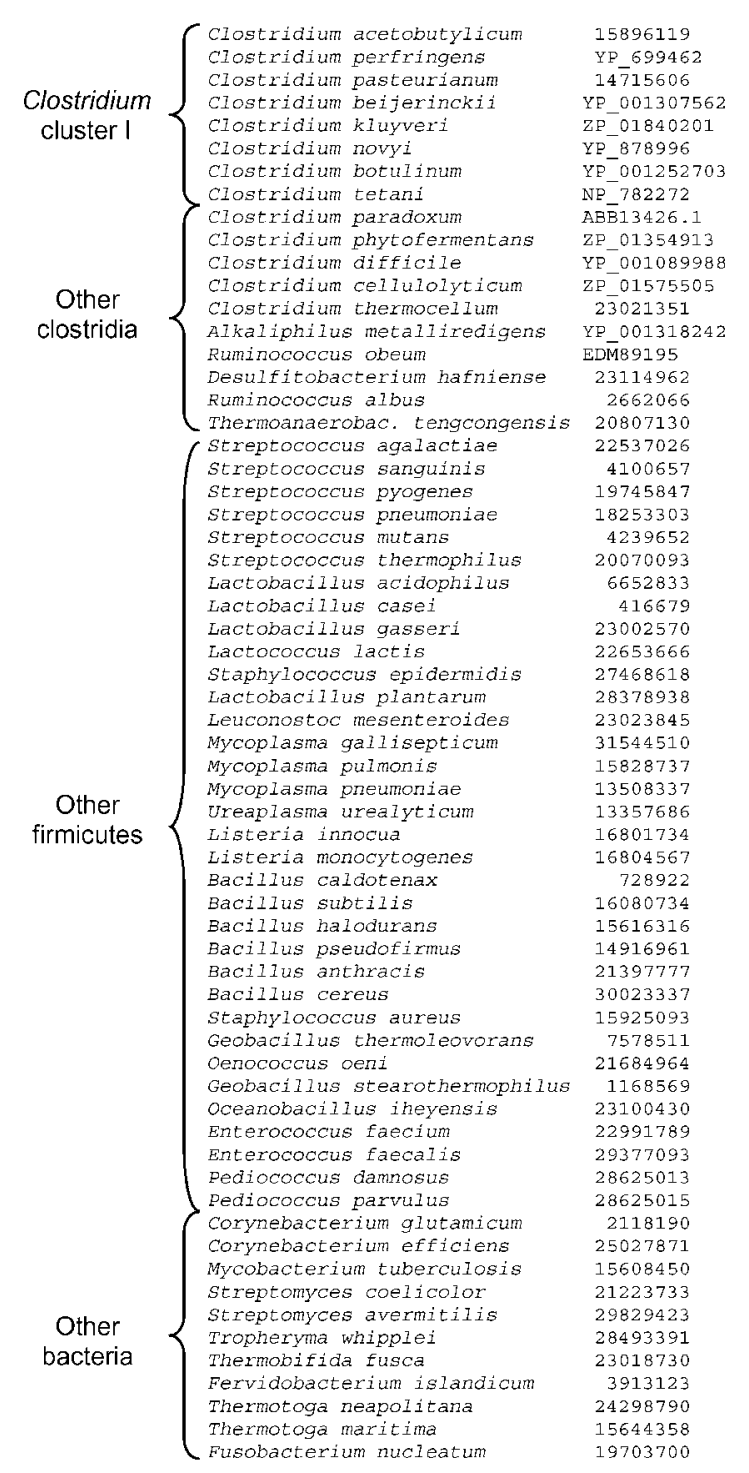

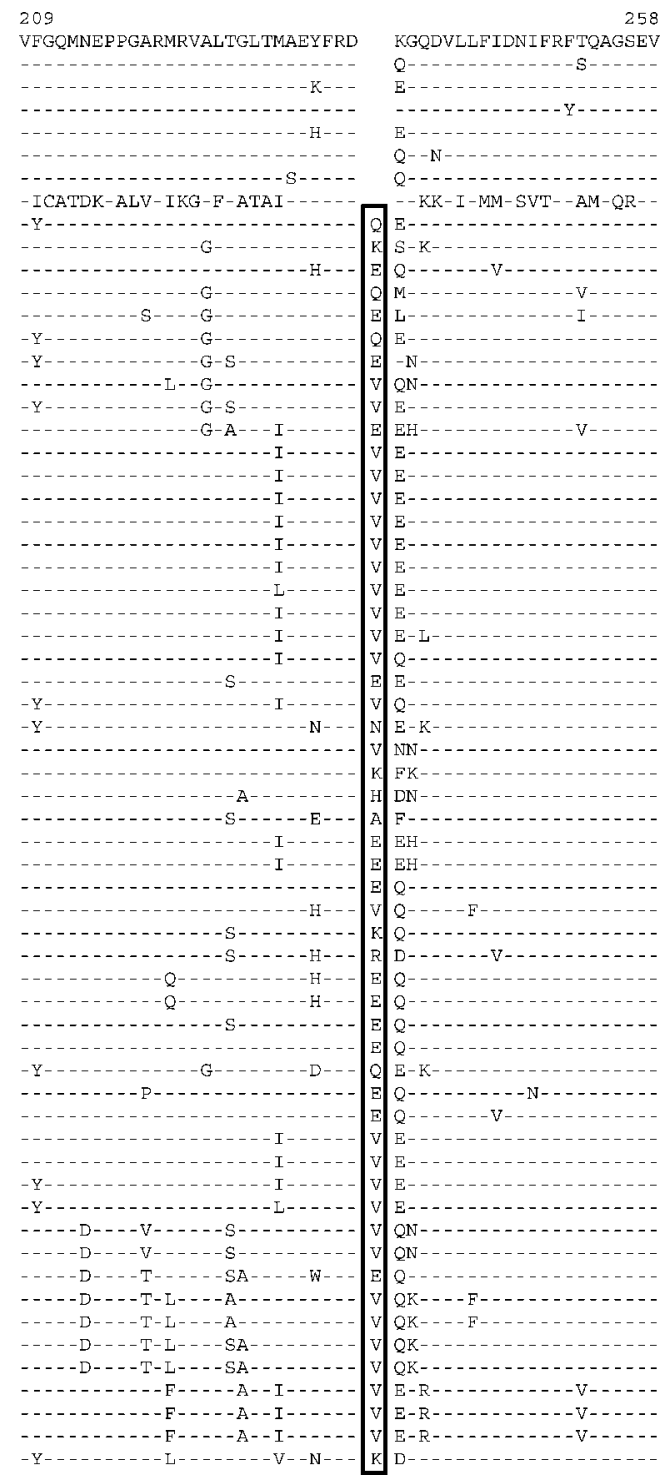

Fig. 3. Partial sequence alignment of ATP synthase beta subunit homologues showing a 1 aa deletion (corresponding region in other species is boxed) that is found uniquely in all of the species of Clostridium cluster I for which a sequence was available, but not found in any other bacteria. 
1992; Gupta, 1998; Rokas \& Holland, 2000). We have identified a number of conserved indels in important proteins that are helpful in defining and circumscribing a number of clades of the clostridia, including cluster I.

The DNA topoisomerases play an essential role in DNA replication and transcription processes by maintaining appropriate levels of supercoiling in chromosomal DNA (Levine et al., 1998; Corbett \& Berger, 2004). Of these, the type II isomerases make transient double-strand breaks in the DNA to allow another strand to pass through it. Our sequence alignment and BLAST searches on the gyrase A protein have revealed that all sequenced cluster I Clostridium species (C. tetani, C. botulinum, C. kluyveri, C. acetobutylicum, C. novyi, C. perfringens and $C$. beijerinckii) contain two different homologues of the protein. A partial sequence alignment of these proteins from various clostridia, firmicutes and some other bacteria is presented in Fig. 2. In one of these homologues (which is variously annotated as GyrA, GyrA2, DNA topoisomerase
IV subunit A and ParC), all species of Clostridium cluster I contain a 4 aa insert in a highly conserved region that is not found in any other clostridia or other groups of bacteria. Detailed BLAST searches with the insert-containing homologue confirm that this insert is a distinctive characteristic of the species of Clostridium cluster I. Two different kinds of type II DNA topoisomerases (DNA gyrase and Topo IV), which carry out similar but not identical functions (Levine et al., 1998; Corbett \& Berger, 2004), have been identified in some bacteria. BLAST searches with either the insert-containing or the insert-lacking homologues show that the top 100 hits in both cases all correspond to the gyrase A subunit from various bacteria. These results indicate that both of these homologues correspond to the gyrase A subunit, although the possibility that one of them (i.e. insert-containing) could be involved in Topo IV function cannot be excluded.

Two other conserved indels that are specific for cluster I of Clostridium are present in the proteins ATP synthase beta

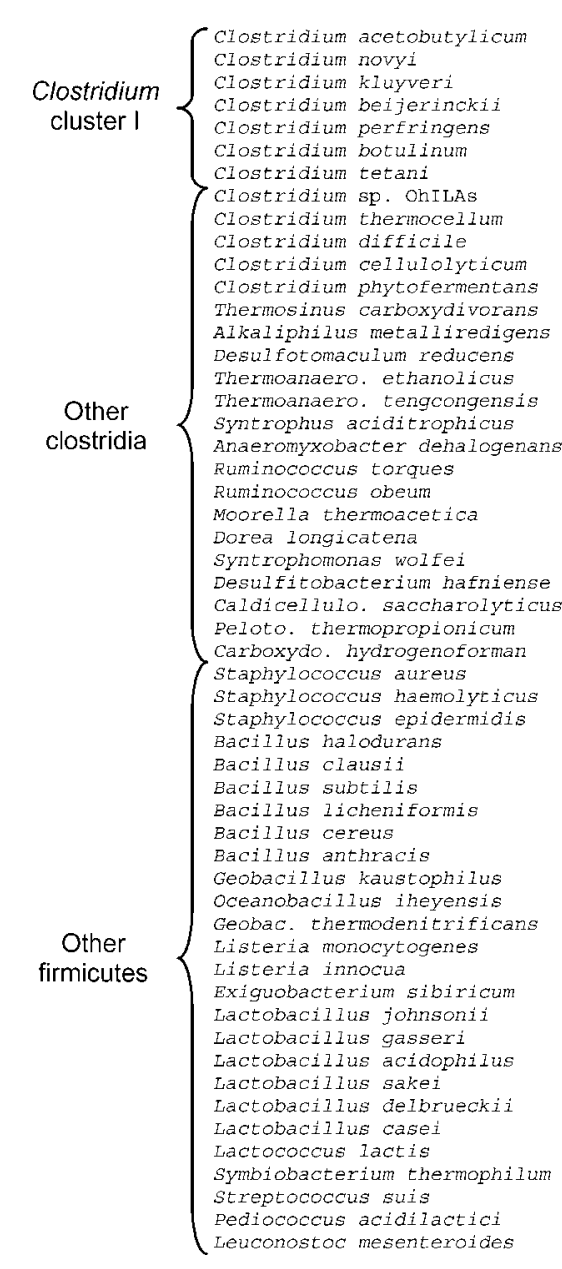

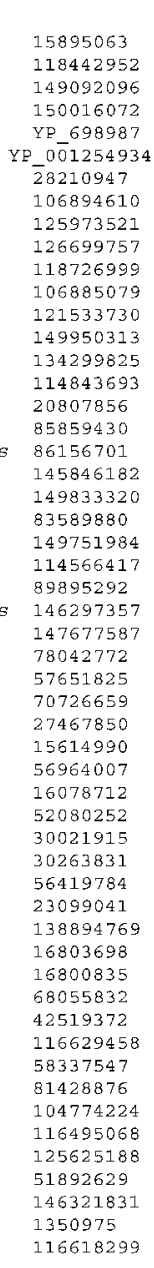

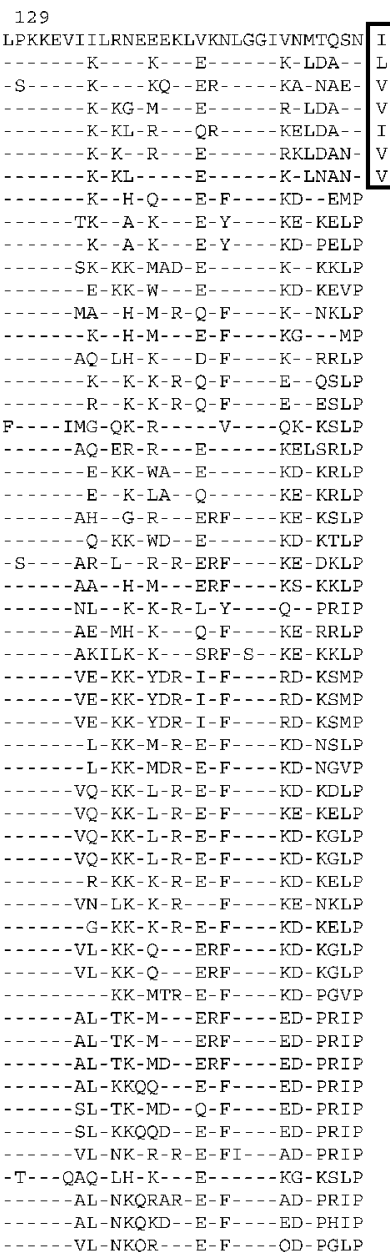

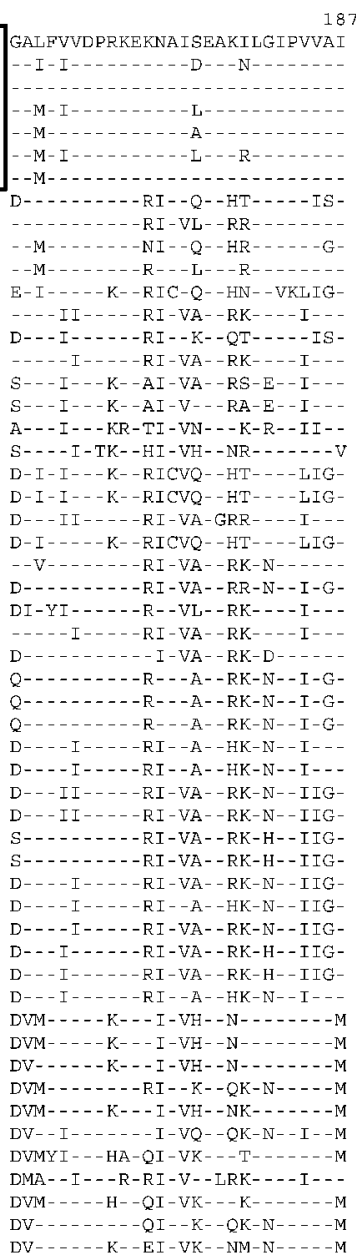

Fig. 4. Partial sequence alignment of ribosomal protein $S 2$ homologues showing a 1 aa insert (boxed) that is specific for the species of Clostridium cluster I for which a sequence was available and not found in any other bacteria. Sequence information for only representative species is presented. 
subunit (Fig. 3) and ribosomal protein S2 (Fig. 4). In the former case, a 1 aa deletion in a highly conserved region is present in all of the cluster I species but it is not found in any of the other Clostridium species (Clostridium paradoxum, C. phytofermentans $\operatorname{ISDg}^{\mathrm{T}}$, C. difficile 630, C. cellulolyticum and C. thermocellum ATCC $27405^{\mathrm{T}}$ ) that do not form part of this cluster. This indel is also not found in any other bacteria, indicating that it is a deletion in the cluster I species. Similarly, in the ribosomal protein S2, a 1 aa insert is present in a conserved region in all cluster I Clostridium species, but it is not found in any of the other Clostridium species (Clostridium sp. OhILAs, C. phytofermentans, C. difficile 630, C. cellulolyticum, C. thermocellum) or other bacteria. Both of these indels are therefore distinctive characteristics of the cluster I species.

An additional conserved indel that serves to define and circumscribe another cluster of the clostridia has been identified in the enzyme phosphoglycerate dehydrogenase, which carries out the first and rate-limiting step in the phosphorylated pathway of serine biosynthesis (McKitrick \& Pizer, 1980). In this case, a 7-9 aa insert is found uniquely in C. thermocellum, T. pseudethanolicus, $T$. tengcogensis and Caldicellulosiruptor saccharolyticus homologues, but is absent in all of the cluster I species, C. difficile and various other bacteria (Fig. 5). The group of species that contain this insert form a well-defined clade in phylogenetic trees based on both sets of concatenated sequences (Fig. 1 and Supplementary Fig. S1). Thus, it is highly likely that this insert was introduced in a common ancestor of this clade of species, and it serves to define this clade or subgroup of clostridia in molecular terms.

\section{Whole proteins that are specific for Clostridium and the cluster I species}

We have also carried out systematic BLAST searches on various open reading frames in the genomes of $C$. tetani E88 and C. perfringens SM101 to identify proteins that are found uniquely in Clostridium species at various phylogenetic depths. These studies have identified many proteins that are found uniquely in Clostridium species. As expected, based on earlier work (Shimizu et al., 2002; Brüggemann et al., 2003; Myers et al., 2006), a large number of proteins (151 for C. perfringens and 86 for C. tetani) are found only in these particular Clostridium species (Supplementary Table S3). For C. perfringens, of which multiple strains have been sequenced (Shimizu et al., 2002; Myers et al., 2006), most of these proteins are present in all sequenced strains. Fifteen additional proteins are found only in $C$. perfringens and $C$. beijerinckii and another group of 15 proteins are specific for C. tetani and C. botulinum (Table 1). In the phylogenetic trees based on concatenated proteins (Fig. 1 and Supplementary Fig. S1), C. perfringens and $C$. beijerinckii form a distinct clade that is supported by high

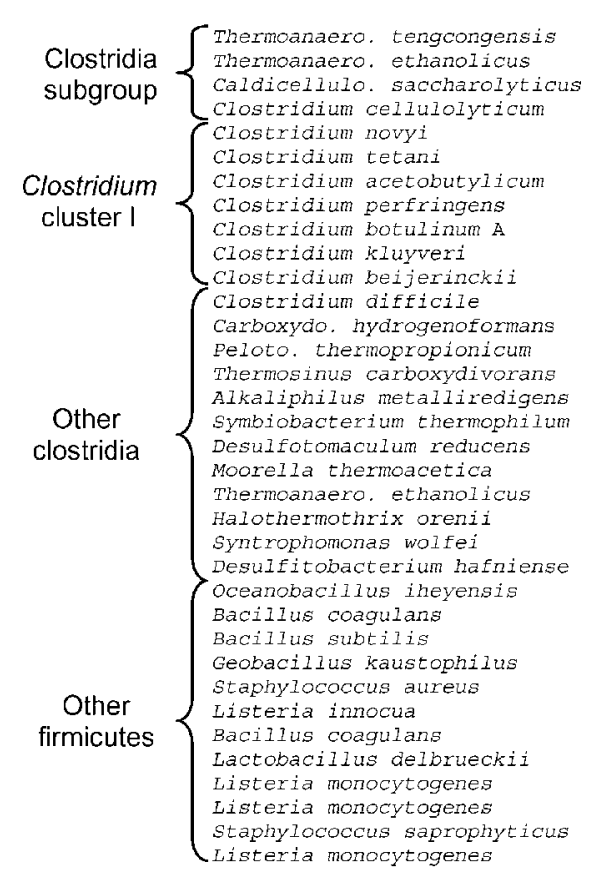





Fig. 5. Partial sequence alignment of phosphoglycerate dehydrogenase homologues showing a 7-9 aa insert that is only found in the homologues from C. thermocellum, T. pseudethanolicus, T. tengcogensis and Caldicellulosiruptor saccharolyticus. The insert in C. thermocellum contains three amino acids (KKP) at the position marked with *. The species containing this insert form a well-defined clade in the phylogenetic tree (Fig. 1) and this molecular signature appears to be a distinctive characteristic of this clade. 
Table 1. Proteins unique to certain species within Clostridium cluster I

All significant BLASTP hits for these proteins are for the Clostridium species indicated.

\begin{tabular}{|lc|}
\hline Genome ID & NCBI protein accession \\
& no. \\
\hline Proteins specific to C. perfringens & \\
and C. beijerinckii & \\
CPR_0643 & \\
CPR_1211 & YP_697970 \\
CPR_1369 & YP_698533 \\
CPR_1378 & YP_698689 \\
CPR_1393 & YP_698697 \\
CPR_1451 & YP_698712 \\
CPR_1468 & YP_698770 \\
CPR_1498 & YP_698787 \\
CPR_1503 & YP_698817 \\
CPR_1802 & YP_698822 \\
CPR_1926 & YP_699117 \\
CPR_1932 & YP_699236 \\
CPR_2321 & YP_699242 \\
CPR_2574 & YP_699587 \\
CPR_2634 & YP_699821 \\
Proteins specific to C. tetani E88 & YP_699871 \\
and C. botulinum & \\
CTC01928 & \\
CTC02107 & NP_782502 \\
CTC00547 & NP_782668 \\
CTC00615 & NP_781230 \\
CTC01032 & NP_781291 \\
CTC01093 & NP_781681 \\
CTC01095 & NP_781738 \\
CTC01096 & NP_781740 \\
CTC01097 & NP_781741 \\
CTC01101 & NP_7817482 \\
CTC01102 & NP_781745 \\
CTC01104 & NP_781746 \\
CTC01105 & NP_781748 \\
CTC01167 & \\
CTC01696 & NP_781749 \\
& \\
\hline
\end{tabular}

(97-100\%) bootstrap scores. Likewise, C. tetani and C. botulinum are also indicated as close relatives in these trees (Fig. 1 and Supplementary Fig. S1). The unique shared presence of these proteins in these species provides further evidence of their close evolutionary relationship.

Of particular interest in the present context is that we have identified 10 proteins that are found uniquely in all of the genome sequences from species of Clostridium cluster I ( $C$. tetani, C. botulinum, C. kluyveri, C. acetobutylicum, C. novyi, C. perfringens and C. beijerinckii) (Table 2). No significant BLAST hit for these proteins was detected in any other bacteria. Nine additional proteins included in Table 2 are also specific for the cluster I species, but they are missing from one or two of the seven sequenced genomes.
Table 2. Proteins that are found uniquely in the species of Clostridium cluster I

Unless otherwise indicated, all significant hits in BLASTP searches for these proteins are from Clostridium cluster I species (i.e. genus Clostridium sensu stricto) and, unless otherwise noted, homologues of these proteins are present in all of the sequenced cluster I species $(C$. tetani E88, C. kluyveri DSM 555 ${ }^{\mathrm{T}}$, C. botulinum, C. perfringens, C. novyi NT, C. acetobutylicum ATCC $824^{\mathrm{T}}$, C. beijerinckii NCIMB $8052^{\mathrm{T}}$ ). For C. botulinum and C. perfringens, most of these protein sequences are found in all sequenced strains (C. perfringens: SM101, ATCC $13124^{\mathrm{T}}$, strain 13; C. botulinum: A strain ATCC 19397, A ATCC 3502. A strain Hall, A3 strain Loch Maree, B1 strain Okra and F strain Langeland).

\begin{tabular}{|c|c|c|}
\hline Genome ID & Accession no. & Possible function \\
\hline СТC00252 & NP_780961 & Hypothetical \\
\hline СТC00303 & NP_781008 & Membrane protein \\
\hline СТС00970 & NP_781622 & Hypothetical \\
\hline СТС00991 & NP_781641 & Hypothetical \\
\hline СТС01016 & NP_781665 & Lipoprotein \\
\hline СТC01297 & NP_781926 & Hypothetical \\
\hline СТC01645 & NP_782249 & Hypothetical \\
\hline СTC01740 & NP_782335 & Hypothetical \\
\hline СТC02077 & NP_782639 & Hypothetical \\
\hline СТC02157 & NP_782713 & Hypothetical \\
\hline CTC00178 $8^{a_{\star}}$ & NP_780892 & Hypothetical \\
\hline CTC0181 ${ }^{a b}$ & NP_780895 & Hypothetical \\
\hline СТC00294 ${ }^{c}$ & NP_781000 & Hypothetical \\
\hline CTC00345 ${ }^{d}$ & NP_781047 & Hypothetical \\
\hline CTC01053 ${ }^{b}$ & NP_781699 & Hypothetical \\
\hline CTC01597 ${ }^{a c}$ & NP_782205 & Hypothetical \\
\hline CTC02136 $6^{b c}$ & NP_782695 & Hypothetical \\
\hline CTC02138 & NP_782697 & Hypothetical \\
\hline СТC02222 † & NP_782769 & Hypothetical \\
\hline
\end{tabular}

${ }^{\star}$ Protein missing from the genome sequence of the following species: a, C. beijerinckii; b, C. novyi; c, C. perfringens; $d$, C. botulinum. $\dagger$ Significant hit also observed in Solibacter usitatus.

The species distribution of these proteins indicates that the genes for them probably evolved in a common ancestor of the species of Clostridium cluster I.

\section{DISCUSSION}

The results presented here confirm that the species of Clostridium cluster I form a phylogenetically cohesive group and that they are distinct from other Clostridium species that do not form part of this well-defined clade. Our comparative genomic analyses have also identified a large number of molecular characteristics, consisting of conserved indels and whole proteins, that are distinctive characteristics of the species of Clostridium cluster I. These newly identified molecular markers further confirm the distinctness of the species of Clostridium cluster I and they strongly support the proposal of recognizing only species 
belonging to this cluster as true Clostridium species, i.e. Clostridium sensu stricto. Based upon these results, the species from this group are distinct not only in phylogenetic terms but also in molecular and, by inference, biochemical terms. These molecular markers now provide new tools to define and circumscribe the genus Clostridium sensu stricto in more definitive molecular terms.

Sequence information for these newly identified molecular characteristics is presently limited to only those species whose genomes have been sequenced. In order to confirm and validate the usefulness of these molecular markers as distinctive characteristics of the genus Clostridium sensu stricto, it will be necessary to obtain sequence information for them from both other clostridia belonging to cluster I and those that fall outside its radiation. It will be particularly interesting to obtain sequence information for these signatures for a number of species belonging to the other clostridial genera (e.g. Anaerobacter polyendosporus, Eubacterium moniliforme, Eubacterium tarantellae, Sarcina ventriculi and Sarcina maxima) that branch within cluster I (Wiegel et al., 2006). The presence of these Clostridium-specific signatures in these species would provide a strong case for their transfer to the genus Clostridium. Because all of the conserved indels described here are found in highly conserved regions, it should be possible to obtain sequence information for these signatures from other species by using degenerate PCR primers flanking the indel-containing regions, as described in our other work (Griffiths et al., 2005; Gao \& Gupta, 2005).

The cellular functions of virtually all of the proteins that are specific either for a given Clostridium species or for cluster I are presently not known. In a few cases, a putative function has been ascribed. However, based on the fact that these proteins do not exhibit significant similarity to proteins from other species, it is highly likely that they may carry out entirely different cellular functions (Galperin \& Koonin, 2004). For the proteins that are specific to Clostridium cluster I, their persistence in all sequenced species from this clade and generally high degree of sequence conservation strongly suggest that they play important functions within this group of bacteria (Fang et al., 2005). Since cluster I includes many important human and animal pathogens, functional studies on these conserved proteins will be of much interest.

\section{ACKNOWLEDGEMENTS}

This work was supported by a research grant from the Canadian Institute of Health Research.

\section{REFERENCES}

Altschul, S. F., Madden, T. L., Schaffer, A. A., Zhang, J., Zhang, Z., Miller, W. \& Lipman, D. J. (1997). Gapped BLAST and PSI-BLAST: a new generation of protein databases search programs. Nucleic Acids Res 25, 3389-3402.
Belda, E., Moya, A. \& Silva, F. J. (2005). Genome rearrangement distances and gene order phylogeny in $\gamma$-proteobacteria. Mol Biol Evol 22, 1456-1467.

Bettegowda, C., Huang, X., Lin, J., Cheong, I., Kohli, M., Szabo, S. A., Zhang, X., Diaz, L. A., Jr, Velculescu, V. E. \& other authors (2006). The genome and transcriptomes of the anti-tumor agent Clostridium novyi NT. Nat Biotechnol 24, 1573-1580.

Binnewies, T. T., Motro, Y., Hallin, P. F., Lund, O., Dunn, D., La, T., Hampson, D. J., Bellgard, M., Wassenaar, T. M. \& Ussery, D. W. (2006). Ten years of bacterial genome sequencing: comparativegenomics-based discoveries. Funct Integr Genomics 6, 165-185.

Brown, J. R. \& Volker, C. (2004). Phylogeny of $\gamma$-proteobacteria: resolution of one branch of the universal tree? Bioessays 26, 463468.

Brüggemann, H., Bäumer, S., Fricke, W. F., Wiezer, A., Liesegang, H., Decker, I., Herzberg, C., Martinez-Arias, R., Merkl, R. \& other authors (2003). The genome sequence of Clostridium tetani, the causative agent of tetanus disease. Proc Natl Acad Sci U S A 100, 1316-1321.

Castresana, J. (2000). Selection of conserved blocks from multiple alignments for their use in phylogenetic analysis. Mol Biol Evol 17, 540-552.

Cato, E. P. \& Stackebrandt, E. (1989). Taxonomy and phylogeny. In Clostridia, pp. 1-26. Edited by N. P. Minton \& D. J. Clarke. New York: Plenum Press.

Cato, E. P., George, W. L. \& Finegold, S. M. (1986). Genus Clostridium Prazmowski 1880, 23 ${ }^{\mathrm{AL}}$. In Bergey's Manual of Systematic Bacteriology, vol. 2, pp. 1141-1200. Edited by P. H. A. Sneath, N. S. Mair, M. E. Sharpe \& J. G. Holt. Baltimore: Williams \& Wilkins.

Ciccarelli, F. D., Doerks, T., von Mering, C., Creevey, C. J., Snel, B. \& Bork, P. (2006). Toward automatic reconstruction of a highly resolved tree of life. Science 311, 1283-1287.

Collins, M. D., Lawson, P. A., Willems, A., Cordoba, J. J., FernandezGarayzabal, J., Garcia, P., Cai, J., Hippe, H., Farrow, J. A. E. \& other authors (1994). The phylogeny of the genus Clostridium: proposal of five new genera and eleven new species combinations. Int $J$ Syst Bacteriol 44, 812-826.

Corbett, K. D. \& Berger, J. M. (2004). Structure, molecular mechanisms, and evolutionary relationships in DNA topoisomerases. Annu Rev Biophys Biomol Struct 33, 95-118.

Fang, G., Rocha, E. \& Danchin, A. (2005). How essential are nonessential genes? Mol Biol Evol 22, 2147-2156.

Finegold, S. M., Song, Y. \& Liu, C. (2002). Taxonomy - general comments and update on taxonomy of clostridia and anaerobic cocci. Anaerobe 8, 283-285.

Galperin, M. Y. \& Koonin, E. V. (2004). 'Conserved hypothetical' proteins: prioritization of targets for experimental study. Nucleic Acids Res 32, 5452-5463.

Gao, B. \& Gupta, R. S. (2005). Conserved indels in protein sequences that are characteristic of the phylum Actinobacteria. Int J Syst Evol Microbiol 55, 2401-2412.

Gao, B., Parmanathan, R. \& Gupta, R. S. (2006). Signature proteins that are distinctive characteristics of Actinobacteria and their subgroups. Antonie van Leeuwenhoek 90, 69-91.

Griffiths, E. \& Gupta, R. S. (2004). Distinctive protein signatures provide molecular markers and evidence for the monophyletic nature of the Deinococcus-Thermus phylum. J Bacteriol 186, 3097-3107.

Griffiths, E., Petrich, A. \& Gupta, R. S. (2005). Conserved indels in essential proteins that are distinctive characteristics of Chlamydiales and provide novel means for their identification. Microbiology 151, 2647-2657. 
Griffiths, E., Ventresca, M. S. \& Gupta, R. S. (2006). BLAST screening of chlamydial genomes to identify signature proteins that are unique for the Chlamydiales, Chlamydiaceae, Chlamydophila and Chlamydia groups of species. BMC Genomics 7, 14.

Gupta, R. S. (1998). Protein phylogenies and signature sequences: a reappraisal of evolutionary relationships among archaebacteria, eubacteria, and eukaryotes. Microbiol Mol Biol Rev 62, 1435-1491.

Gupta, R. S. (2006). Molecular signatures (unique proteins and conserved indels) that are specific for the epsilon proteobacteria (Campylobacterales). BMC Genomics 7, 167.

Gupta, R. S. \& Griffiths, E. (2006). Chlamydiae-specific proteins and indels: novel tools for studies. Trends Microbiol 14, 527-535.

Gupta, R. S. \& Lorenzini, E. (2007). Phylogeny and molecular signatures (conserved proteins and indels) that are specific for the Bacteroidetes and Chlorobi species. BMC Evol Biol 7, 71.

Gupta, R. S. \& Mok, A. (2007). Phylogenomics and signature proteins for the alpha Proteobacteria and its main groups. BMC Microbiol 7, 106.

Harris, J. K., Kelley, S. T., Spiegelman, G. B. \& Pace, N. R. (2003). The genetic core of the universal ancestor. Genome Res 13, 407-412.

Jeanmougin, F., Thompson, J. D., Gouy, M., Higgins, D. G. \& Gibson, T. J. (1998). Multiple sequence alignment with CLUSTAL_X. Trends Biochem Sci 23, 403-405.

Johnson, J. L. \& Francis, B. S. (1975). Taxonomy of the clostridia: ribosomal ribonucleic acid homologies among the species. $J$ Gen Microbiol 88, 229-244.

Koonin, E. V. \& Galperin, M. Y. (1997). Prokaryotic genomes: the emerging paradigm of genome-based microbiology. Curr Opin Genet Dev 7, 757-763.

Lawson, P. A., Llop-Perez, P., Hutson, R. A., Hippe, H. \& Collins, M. D. (1993). Towards a phylogeny of the clostridia based on 16S rRNA sequences. FEMS Microbiol Lett 113, 87-92.

Levine, C., Hiasa, H. \& Marians, K. J. (1998). DNA gyrase and topoisomerase IV: biochemical activities, physiological roles during chromosome replication, and drug sensitivities. Biochim Biophys Acta 1400, 29-43.

McKitrick, J. C. \& Pizer, L. I. (1980). Regulation of phosphoglycerate dehydrogenase levels and effect on serine synthesis in Escherichia coli K-12. J Bacteriol 141, 235-245.

Myers, G. S., Rasko, D. A., Cheung, J. K., Ravel, J., Seshadri, R., DeBoy, R. T., Ren, Q., Varga, J., Awad, M. M. \& other authors (2006). Skewed genomic variability in strains of the toxigenic bacterial pathogen, Clostridium perfringens. Genome Res 16, 1031-1040.

Nolling, J., Breton, G., Omelchenko, M. V., Makarova, K. S., Zeng, Q., Gibson, R., Lee, H. M., Dubois, J., Qiu, D. \& other authors (2001). Genome sequence and comparative analysis of the solvent-producing bacterium Clostridium acetobutylicum. J Bacteriol 183, 4823-4838.

Rivera, M. C. \& Lake, J. A. (1992). Evidence that eukaryotes and eocyte prokaryotes are immediate relatives. Science 257, 74-76.
Rokas, A. \& Holland, P. W. (2000). Rare genomic changes as a tool for phylogenetics. Trends Ecol Evol 15, 454-459.

Rokas, A., Williams, B. L., King, N. \& Carroll, S. B. (2003). Genomescale approaches to resolving incongruence in molecular phylogenies. Nature 425, 798-804.

Rood, J. I. (2006). Clostridium perfringens and histologic disease. In The Prokaryotes: a Handbook on the Biology of Bacteria, 3rd edn, vol. 4, pp. 753-770. Edited by M. Dworkin, S. Falkow, E. Rosenberg, K. H. Schleifer \& E. Stackebrandt. New York: Springer.

Schaffer, A. A., Aravind, L., Madden, T. L., Shavirin, S., Spouge, J. L., Wolf, Y. I., Koonin, E. V. \& Altschul, S. F. (2001). Improving the accuracy of PSI-BLAST protein database searches with compositionbased statistics and other refinements. Nucleic Acids Res 29, 29943005.

Schmidt, H. A., Strimmer, K., Vingron, M. \& von Haeseler, A. (2002). TREE-PUZZLE: maximum likelihood phylogenetic analysis using quartets and parallel computing. Bioinformatics 18, 502-504.

Sebaihia, M., Wren, B. W., Mullany, P., Fairweather, N. F., Minton, N., Stabler, R., Thomson, N. R., Roberts, A. P., Cerdeño-Tárraga, A. M. \& other authors (2006). The multidrug-resistant human pathogen Clostridium difficile has a highly mobile, mosaic genome. Nat Genet 38, 779-786.

Sebaihia, M., Peck, M. W., Minton, N. P., Thomson, N. R., Holden, M. T., Mitchell, W. J., Carter, A T., Bentley, S. D., Mason, D. R. \& other authors (2007). Genome sequence of a proteolytic (group I) Clostridium botulinum strain Hall A and comparative analysis of the clostridial genomes. Genome Res 17, 1082-1092.

Seedorf, H., Fricke, W. F., Veith, B., Brüggemann, H., Liesegang, H., Strittmatter, A., Miethke, M., Buckel, W., Hinderberger, J. \& other authors (2008). The genome of Clostridium kluyveri, a strict anaerobe with unique metabolic features. Proc Natl Acad Sci U S A 105, 21282133.

Shimizu, T., Ohtani, K., Hirakawa, H., Ohshima, K., Yamashita, A., Shiba, T., Ogasawara, N., Hattori, M., Kuhara, S. \& Hayashi, H. (2002). Complete genome sequence of Clostridium perfringens, an anaerobic flesh-eater. Proc Natl Acad Sci U S A 99, 996-1001.

Stackebrandt, E., Kramer, I., Swiderski, J. \& Hippe, H. (1999). Phylogenetic basis for a taxonomic dissection of the genus Clostridium. FEMS Immunol Med Microbiol 24, 253-258.

Tamura, K., Dudley, J., Nei, M. \& Kumar, S. (2007). MEGA4: molecular evolutionary genetics analysis (MEGA) software version 4.0. Mol Biol Evol 24, 1596-1599.

Van de Peer, Y. \& De Wachter, R. (1994). TREECON for Windows: a software package for the construction and drawing of evolutionary trees for the Microsoft Windows environment. Comput Appl Biosci 10, 569-570.

Wiegel, J., Tanner, R. \& Rainey, F. A. (2006). An introduction to the family Clostridiaceae. In The Prokaryotes: a Handbook on the Biology of Bacteria, 3rd edn, vol. 4, pp. 654-678. Edited by M. Dworkin, S. Falkow, E. Rosenberg, K. H. Schleifer \& E. Stackebrandt. Springer: New York. 